\title{
Noteworthy COLlections: Florida
}

Barry A. Rice - Center for Plant Diversity - University of California - One Shields Avenue - Davis, California $95616 \cdot$ USA • bamrice@ ucdavis.edu

D rosera filiformis R af. $x$ tracyi M acf. (D roseraceae) - southeastern Washington County, Florida, elevation 20 m, 29 M ay 2010. Plants were found flowering on the wet borders of a low, sandy lake, with $\mathrm{D}$ rosera filiformis Raf. and D rosera tracyi M acf.

\section{Previous K nowledge}

This represents the first collection of this plant in the wild. One parent plant, D rosera tracyi, occurs al ong the Gulf Coast, from L ouisiana (historical only - the plant has not been collected for at least 30 years) through M ississippi, A labama, the panhandle of Florida, and into southwestern Georgia.

The other parent plant, D rosera filiformis, occurs in widely scattered locations along the A tlantic Coast, with records for N ova Scotia, M assachusetts, R hode Island (probably extinct), Connecticut (historical only), N ew York, N ew Jersey, and M aryland, then after large range gaps the plant reappears in North Carolina and northwestern Florida. Reports from Delaware and South Carolina appear to be anecdotal. It has been collected from adjacent counties in WestV irginia and Pennsylvania, but these plants are believed to be introduced. Both D rosera filiformis and D rosera tracyi have been introduced to other states by horticulturists, as well.

The populations of D rosera filiformis in Florida are of considerable interest; I have been studying these plants for several years, and a discussion of them will be published separately.

\section{Significance}

The only opportunity for natural overlap of the two parent species is in Florida (B ay and Washington Counties). A single location has been documented where both species occur together, but a 1990 herbarium specimen from this site indicates that there is "no sign of intergradation" (L.C.A nderson, 183046; FSU ). In 2010 I visited this location, accompanied by Elizabeth M. Salvia. D espite careful searches only D rosera filiformis was observed; no D rosera tracyi or hybrids were detected.

In 2008-2009, a number of carnivorous plant enthusiasts ( $M$ akoto Honda, Jim M iller, Randy Zerr) reported a site where both species occur, and where hybridization was reportedly occurring. In 2010 I visited this location with B rian B arnes, J im M iller, Elizabeth Salvia, and Randy Zerr, and observed both parent species. Furthermore, a hybrid swarm was visible with at least hundreds of plants present. The full extent of the population could not be assessed because our team was driven from the site by electrical storms.

The hybrid nature of the plants was evident because the plants were very large (leaf lengths approximately $25-28 \mathrm{~cm}$; inflorescence lengths approximately $43-50 \mathrm{~cm}$ ). This is larger than is typical for D rosera filiformis, but is more typical for Drosera tracyi. M eanwhile, the gland tentacles and leaf blades were suffused with pale red pigmentation. This pigmentation is absent in D rosera tracyi, while it is darker red in D rosera filiformis. The hybrid (involving Floridian D rosera filiformis) has been made in cultivation by B rian Barnes, and has similar characteristics.

The hybrids were producing large numbers of seeds, although many of the seeds had aborted and were only approximately 1/4-1/3 normal size. Similarly, a cultivar (D rosera 'California Sunset') was made by a horticulturist in 1973, and is demonstrably fertile.

Voucher specimens have been submitted to the University of California, Davis (DAV), \#B R 100502, and Florida State U niversity, Tallahassee (FSU), \#B R 100503. Color photographs from the 2010 trip can be seen at http://www.sarracenia.com. 